\title{
Tuberculosis and HIV: light after darkness
}

The serious public health consequences of the interaction between tuberculosis and HIV infection have received much attention in the scientific and public press. Predicting future trends in the morbidity and mortality of this "cursed duet" has been likened to a game of blind man's buff. ${ }^{1}$ On the other hand, there are grounds for hope of a ray of light in the present darkness in the form of novel immunotherapeutic interventions. Indeed, it may even be possible to prevent and treat HIV infection and tuberculosis in an identical manner.

This challenging possibility is raised by observations that not all those exposed to either the tubercle bacillus or to HIV develop overt disease. In the case of tuberculosis this has been evident for decades and there is increasing evidence that harmless, and possibly protective, encounters with HIV can occur. ${ }^{23}$ The implication of these findings is that the human immune system can, in some cases, deal effectively with these infections. If an encounter with a pathogen may lead either to disease or to long lasting protective immunity, the immune system must be able to respond to such an encounter in different, and possibly mutually exclusive, ways. The concept that infection by the tubercle bacillus leads to distinct and probably incompatible immune reactions has a long and convoluted history.

In 1891 Koch demonstrated that the injection of tuberculin into the skin of a guinea pig previously infected with Mycobacterium tuberculosis led to a tissue necrotising reaction. This became known as the Koch phenomenon and was for many years regarded as a classical example of a delayed hypersensitivity reaction though, as explained below, we would now distinguish between this necrotising reaction and the non-necrotising delayed hypersensitivity reaction seen in other circumstances. Subsequently, von Pirquet used reactivity to tuberculin as the basis of a skin test - the tuberculin test - to indicate infection by the tubercle bacillus. During his extensive studies von Pirquet noticed that patients with disseminated tuberculosis or with other infections that predisposed to active tuberculosis frequently became tuberculin negative, thereby giving rise to the notion that tuberculin reactivity was an indicator of protection against tuberculosis. ${ }^{4}$ This assertion persisted for several decades and the term "delayed hypersensitivity" - used indiscriminately for both the Koch phenomenon and non-necrotising delayed hypersensitivity - has often been regarded as synonymous with the term "cell mediated immunity." Indeed, the concept that, in order to induce protective immunity BCG must be given in a large enough dose to induce tuberculin reactivity, has only recently been questioned. ${ }^{5}$

Debré and Bonnet in 1916 were the first to recognise that a mycobacterial challenge could, in fact, induce two quite distinct tissue responses. ${ }^{6}$ Soon afterwards Rich and McCordock refuted the hypothesis that tuberculin reactivity is a direct correlate of immunity to tuberculosis in man. ${ }^{7}$ This refutation received firm support from experimental work on the guinea pig by Wilson and his colleagues who showed that animals preimmunised with protocols that primed the necrotising Koch phenomenon died more rapidly after challenge by $M$ tuberculosis than non-immunised controls. ${ }^{8}$ These studies highlighted the existence of two types of skin test reactivity and raised another question: if the Koch phenomenon is not a corre- late of protective immunity, what about non-necrotising responses? For many years apparently conflicting data continued to fan the flames of controversy. ${ }^{9}$ For example, while greater than $85 \%$ skin test conversion was observed shortly after vaccination in the 18 controlled trials of BCG against tuberculosis, protection varied from $0 \%$ to $77 \%$ although, of course, the tuberculin status of individuals at the time that successful infection by tubercle bacilli occurred is unknown. Similarly, in the British Medical Council tuberculosis vaccination trials one batch of vole bacillus vaccine induced very few skin test conversions yet protected well against tuberculosis. This, and studies with different strains of BCG, ${ }^{10}$ suggests that post-vaccination tuberculin positivity does not directly correlate with protective immunity in humans. On the other hand, it is clear that small, non-necrotising responses to tuberculin in persons who have not received BCG do correlate with protection. ${ }^{11}$

We are therefore led to conclude that there are two types of response. The first response - the Koch phenomenon causes tissue damage and may, under some circumstances, have a minor protective role by isolating bacteria in necrotic foci. It does not, however, actively destroy tubercle bacilli and thus does not lead to sterilisation of the tissues. The second type of response induces a state of true immunity which may or may not be accompanied by nonnecrotising tuberculin positivity (the latter may merely indicate the extent of ongoing boosting by the relevant epitopes).

Our understanding of these two types of response has increased dramatically with Mosmann's description of the existence of two subpopulations of helper T cells, Th1 and Th2, characterised by distinct cytokine secretion profiles, ${ }^{12}$ and the subsequent realisation that a similar dichotomy in cytokine patterns is seen in CD8 $+\mathrm{T}$ cells. ${ }^{13}$ Thus we can now speak of "type 1" and "type 2" T cells, whether $\mathrm{CD} 4+$ or $\mathrm{CD} 8+$, though little is known of the cytokine patterns of $\mathrm{CD} 8+$ cells in most of the diseases considered here. The predominant helper $\mathrm{T}$ cell type has profound implications for the outcome of Leishmania major infection in mice and, furthermore, the predominant cell type can be determined by vaccination strategies. ${ }^{14}$

It has emerged that, in a number of chronic infections including syphilis, schistosomiasis, downgrading leprosy, and leishmaniasis, there is an initial type 1 response which then shifts to a type 2 response with detriment to the host. ${ }^{15}$ Likewise, Shearer and colleagues have produced evidence that, in HIV infection, Thl responses lead to protection while $\mathrm{Th} 2$ responses lead to susceptibility and eventual progression to AIDS. ${ }^{316}$ It is thus possible that the consequences of HIV infection could be prevented by a vaccination or immunotherapeutic strategy causing a Th2 to Th1 shift in the relevant T helper cell populations. ${ }^{3}$ Such a strategy might not be easily achieved as each of these classes of $T$ helper cells antagonises production of the other. ${ }^{12}$ Observations show, however, that it is possible to derive delayed hypersensitivity mediating $T$ cells specific for an antigen in vitro from a population of lymphocytes immunised to produce copious amounts of IgG antibody specific for this antigen and not expressing detectable delayed hypersensitivity. It therefore appears possible to achieve a modulation of the immune response from a Th2 to a Th1 mode in vitro, and hence probably in 
vivo. Such a modulation in vitro requires the presence of antigen. ${ }^{17}$ One suggested strategy for achieving such a modulation would be to combine appropriate HIV antigens with adjuvants and Th1 enhancing cytokines such as interleukin 12 and gamma interferon (IFN $\gamma$ ), ${ }^{3}$ but this approach could involve much trial and error. Nature, perhaps, has already provided us with such a strategy and this may have been revealed by studies on tuberculosis.

It has been thought for some time that the immune reactions leading to protection and to immunopathology in tuberculosis might be due to different populations of T cells. ${ }^{1819}$ Recent experiments with mice in which the gene for $\beta_{2}$-microglobulin has been incapacitated, so that class I MHC determinants cannot be expressed and $\mathrm{CD} 8+\mathrm{T}$ cells cannot therefore be generated, show that both $\mathrm{CD} 4+$ and CD8 $+\mathrm{T}$ cells are essential for protection against $M$ tuberculosis. ${ }^{20}$ It seems, however, that these $T$ cells need to secrete the type 1 pattern of cytokines since IFN $\gamma$ is crucial to protection. On the other hand, there is clear evidence for type 2 activity in tuberculosis since patients can have specific IgE antibody, ${ }^{21}$ and even an eosinophilia, and the peripheral blood contains $T$ cells that release IL-4 in response to mycobacterial antigen. ${ }^{22}$ Meanwhile, recent work in animal models suggests that necrosis occurs in $\mathrm{T}$ cell-dependent granulomata when the Thl to Th2 shift described above leads to a type 2 response superimposed on a type 1 pattern. This is well documented in schistosomiasis ${ }^{23}$ and may parallel new observations that skin test sites evoked with mycobacterial antigen in preimmunised animals are exquisitely sensitive to cytokine mediated tissue damage if the response is mixed Th1/Th2, but not if it is "pure" Th1. ${ }^{24}$ Are the Koch phenomenon and tissue damage in overt tuberculosis therefore symptoms of the Th1 to Th2 shift and, if so, how can the response be redirected back towards Thl?

Clues as to how tuberculosis could be controlled by immunotherapeutic intervention have come from investigation into the reasons why the protective efficacy of BCG varies so much from region to region. These studies soon revealed that this variation is geographically, rather than racially, determined..$^{25}$ This geographical difference depends, in turn, on the number, species, and immunogenicity of environmental mycobacteria and on the degree of exposure of the human population to them.

In a paper entitled "Original mycobacterial sin" Abrahams showed that exposure to mycobacterial antigens early in life determined subsequent patterns of immune reactivity to such antigens. ${ }^{26}$ Stanford and colleagues subsequently postulated that prior contact with environmental mycobacteria predetermined the type of immune response that would be induced by subsequent BCG vaccination..$^{25}$ Bretscher et al have placed this concept on a sound basis by their demonstration that small doses of antigen, subimmunogenic for the induction of antibody but able to induce a delayed hypersensitivity reaction, can "imprint" the immune system, thereby determining future patterns or pathways of immune reactivity. ${ }^{14}$ In general the smaller the dose, the greater the likelihood of generating a Thl response, so long as this dose is above a minimal threshold.

Our first tentative explanation for the ability of environmental mycobacteria to affect immune responsiveness was that they could "imprint" the immune system with the ability to respond predominantly either to those antigens common to all mycobacteria (group 1 antigens) or to species specific ones (group 4). It was observed that, in general, healthy persons in contact with patients with either tuberculosis or leprosy react in skin testing to agents prepared from any species of mycobacterium, indicating recognition of shared epitopes, while the patients them- selves respond to a limited range of reagents, indicating recognition of species-specific epitopes but diminished responsiveness to the shared epitopes. ${ }^{27} 28$ It also appears that the Koch phenomenon is only evoked by speciesspecific epitopes. ${ }^{29} 30$ The responses to common and speciesspecific antigens thus appear to be different, although this is in conflict with previous observations that there is usually coherence in the regulation of the class of response to the diverse epitopes of a complex antigen. Notwithstanding, according to the concepts outlined above, our data imply that there is a strong Th2 component to the patients' responses to the species-specific epitopes while common epitopes are recognised by $T h 1$ cells that are downregulated in some manner, perhaps by the cytokines released by the Th2 cells. Why, then, does it appear that the common and species-specific epitopes are handled so differently by the immune system? We postulate that three closely related factors are involved.

1. The common epitopes may be inherently different from the species-specific ones. They may, for instance, be stress (heat shock) proteins that appear to play a subtle role in the immune response to many microorganisms.

2. The common epitopes are encountered daily via the gut, and may prime regulatory mechanisms associated with "mucosal immunity."

3. In accordance with Bretscher's concepts ${ }^{5}$ chronic low dose exposure to the common epitopes from the environment may have caused the response to these epitopes to be "locked in" to the Th1 pattern, while the species-specific epitopes of pathogenic mycobacteria are encountered de novo when the patient is infected and are susceptible to the mechanisms causing the Thl to Th2 shift, the Koch phenomenon, and downregulation of the Thl response.

A mycobacterium that would restore recognition of common antigens and, thereby, protective immune responses would therefore be a potential immunotherapeutic agent.

Bacteriological $^{31}$ and skin test studies ${ }^{32}$ in the region of Uganda where BCG affords good protection against leprosy, ${ }^{33}$ studies on leprosy patients and their families, ${ }^{34}$ and a detailed programme of skin testing with reagent mixtures, ${ }^{30}$ have identified $M$ vaccae NCTC 11659 as a strain of special promise. It combines the virtues of a predominance of group 1 (common mycobacterial) epitopes with a regulatory effect on the Koch phenomenon and efficacy as a killed suspension. ${ }^{35}$ Several small open studies and placebo controlled, blinded, randomised trials have shown that $10^{9}$ heat killed $M$ vaccae given by intradermal injection to tuberculosis patients as an adjunct to chemotherapy has beneficial effects. ${ }^{35}$ It reduces the number of deaths occurring during antituberculosis chemotherapy and significantly improves the bacteriological cure rate in those taking a full course of chemotherapy. It markedly improves the cure rate and reduces mortality in those who do not take a full course of chemotherapy, and is also efficacious in the treatment of previous treatment failures and a proportion of patients with multidrug resistant tuberculosis. It also causes a significant fall in the level of an abnormal agalactosyl glycoform of IgG that is associated with active tuberculosis. This IgG glycoform has proved invaluable as an independent biochemical marker of the efficacy of immunotherapy..$^{36}$

At first it was thought that the loss of recognition of common mycobacterial epitopes was unique to mycobacterial disease, but it has recently been demonstrated in HIV infection and in South American trypanosomiasis. ${ }^{37} 38$ It is thus likely, as suggested above, that many of these common epitopes are components of more widely distributed immunogens such as the highly conserved stress or 
heat shock proteins. ${ }^{39}$ Alternatively, these antigens may be restricted to the genus Mycobacterium yet have a nonspecific regulatory activity favouring Thl cells. ${ }^{40}$ In either case $M$ vaccae immunotherapy may effect changes in immune responsiveness of much wider significance than those necessary for affording protection in mycobacterial disease. Indeed, the observation by Ramu et al of the efficacy of such immunotherapy in psoriasis, ${ }^{41}$ and our own preliminary observations of its potential use in the treatment of several other diseases, suggest that this is the case. In particular, a small study in Nigeria of the effect of $M$ vaccae immunotherapy in HIV-related tuberculosis gives rise to hope. ${ }^{42}$ All eight patients who received immunotherapy were alive and well two years later, whereas eight of nine who received placebo were dead. Five of the eight immunotherapy recipients initially had generalised lymphadenopathy but this had resolved in all cases by one year. Most remarkably of all, two recipients of placebo and two of immunotherapy had repeat HIV serological testing after one year: the former were still HIV seropositive but the latter were negative.

There is good evidence that, despite large superficial differences, the underlying immunopathology of mycobacterial diseases, syphilis, schistosomiasis, probably trypanosomiasis and, most intriguing of all, HIV infection is very similar. This is, perhaps, not surprising. Most of the great complexity of the mammalian immune system that has evolved to ward off the slings and arrows of constant environmental challenge is concerned with recognition and regulation. The actual effector mechanisms used by the immune system to crunch microorganisms and bystander host cells are, by contrast, much more limited. It is possible that all these; and probably many other, diseases in which cellular immunity is of paramount importance are the result of the immune system being in the wrong "mode" of reactivity and thus open to a new modality of treatment.

Accordingly, the centre of attention must be the regulation of $\mathrm{T}$ cell maturation. Is this under the control of a complex interaction of antigens or of a simple chemical switch? If the latter is the case a suitable adjuvant, of which $M$ vaccae may prove to be a prime example, could affect a global switch leading to beneficial immune responses in a wide range of diseases.

Reprint requests to: Dr JM Grange.

Department of Microbiology,

National Heart and Lung Institute,

JM GRANGE

Royal Brompton Hospital,

London SW3 6NP, UK

Department of Medical Microbiology

University College London Medical School, London WIP $7 L D, U K$

\section{JL STANFORD GAW ROOK P ONYEBUJOH}

Department of Microbiology,

University of Saskachewan,

Saskatoon,

Saskachewan SK7 OWO

Canada

1 Davies PDO. Tuberculosis and HIV: blind man's buff. Thorax 1993;48:193-4.

2 Clerici M, Berzofski JA, Shearer GM, Tacket CO. Exposure to human immunodeficiency virus type 1 -specific $T$ helper cell responses before detection of infection by polym

3 Salk J, Bretscher PA, Salk PL, Clerici M, Shearer GM. A strategy for prophylactic vaccination against HIV. Science 1993;260:1270-2.

4 von Pirquet C. Verlauf der tuberculosen Allergie bei einen Falle von Masern und Miliartuberkulose. Wien Klin Wschr 1908;21:861-5.

5 Bretscher PA. A strategy to improve the efficacy of vaccination agains tuberculosis and leprosy. Immunol Today 1991;13:342-5.

6 Debré $R$, Bonnet $H$. Surinfection du cobaye tuberculeux et après l'etablissement de l'état allergique. CR Soc Biol 1922;87:449-68.

7 Rich AR, McCordock HA. Enquiry concerning the role of allergy, immu- nity and other factors of importance in the pathogenesis of human tuberculosis. Bull fohns Hopkins Hosp 1929;47:273-422.

8 Wilson GS, Schwabacher H, Maier I. The effect of the desensitisation of tuberculous guinea-pigs. $\mathcal{F}$ Pathol Bacteriol 1940;50:89-109.

9 Bothamley GH, Grange JM. The Koch phenomenon and delayed hypersensitivity: 1891-1991. Tubercle 1991;72:7-11.

10 Fine PEM. The BCG story: lessons from the past and implications for the future. Rev Infect Dis 1989;11(Suppl 2):S353-9.

11 Fine PEM. Immunities in and to tuberculosis: implications for pathogenesis and vaccination. In McAdam KPWJ, Porter JDH, eds. Tuberculosis: back to the future (Proceedings of the London School of Hygiene and back to the future (Precedings of the London Scho Wiley, 1994:53-78.

12 Mosmann TR. Regulation of immune responses by $\mathrm{T}$ cells with different cytokine secretor phenotypes. Role of a new cytokins: cytokine synthesis inhibitory factor (IL-10). Int Arch Allergy Appl Immunol 1991;94:110-5.

13 Flynn JL, Goldstein MM, Triebold KJ, Koller B, Bloom BR. Major histocompatibility complex class I-restricted $T$ cells are required for resistance to Mycobacterium tuberculosis infection. Proc Natl Acad Sci USA 1992;89:12013-7.

14 Bretscher PA, Wei G, Menon JN, Bielefeldt-Ohmann H. Establishment of stable, cell-mediated immunity that makes "susceptible" mice resistant to Leishmania major. Science 1992;257:539-42.

15 Sher A, Gazzinelli RT, Oswald IP, Clerici M, Kullberg M, Pearce EJ, et al. Role of $\mathrm{T}$ cell derived cytokines in the downregulation of immune responses in parasitic and retroviral infection. Immunol Rev responses in paras

16 Shearer GM, Clerici M. A Th1 to Th2 switch is a critical step in the etiology of HIV infection. Immunol Today 1993;14:107-10

17 LeClercq SA, Bretscher PA. T cells expressing delayed-type hypersensitivity can be derived from a humorally immune lymphocyte population. Eur f Immunol 1987;17:949-54.

18 Youmans GP. Relation between delayed hypersensitivity and immunity in tuberculosis. Am Rev Respir Dis 1975;111:109-18.

19 Lefford MJ. Delayed hypersensitivity and immunity in tuberculosis. $\mathrm{Am}$ Rev Respir Dis 1975;111:243-6.

20 Bloom BR, Salgame P, Diamond B. Revisiting and revising suppressor T cells. Immunol Today 1992;13:131-6.

21 Yong AJ, Grange JM, Tee RD, Beck JS, Bothamley GH, Kemeny DM, et $a l$. Total and anti-mycobacterial IgE levels in serum from patients with tuberculosis and leprosy. Tubercle 1989;70:273-9.

22 Surcel HM, Troye-Blomberg M, Paulie S, Andersson G, Moreno C, Pasvol $\mathrm{G}$, et al. Th1/Th2 profiles in tuberculosis based on proliferation and cytokine response of peripheral blood lymphocytes to mycobacterial antigens. Immunology 1994;81:171-6.

23 Grzych JM, Pearce E, Cheever A, Caulada ZA, Caspar P, Henry S, et al. Egg depositio is the stimulus for the production of Th2 cytokines in Egg depositio is the stimulus for the production of Th2 cytoki
murine schistosomiasis mansoni. $f$ Immunol 1991;146:1322-40.

24 Hernandez-Pando R, Rook GAW. The role of TNF $\alpha$ in T cell mediated inflammation depends on the TH1/TH2 cytokine balance. Immunology 1994 (in press)

25 Stanford JL, Shield MJ, Rook GAW. How environmental mycobacteria may predetermine the protective efficacy of BCG. Tubercle 1981;62:5562 .

Abrahams E. "Original mycobacterial sin". Tubercle 1970;51:316-21.

27 Stanford JL, Nye PM, Rook GAW, Samuel N, Fairbank A. A preliminary investigation of the responsiveness or otherwise of patients and staff of a leprosy hospital to groups of shared or specific antigens of mycobacteria. Lepr Rev 1981;52:321-7.

28 Kardjito T, Beck JS, Grange JM, Stanford JL. A comparison of the responsiveness to four new tuberculins among Indonesian patients with pulmonary tuberculosis and healthy subjects. Eur $\mathcal{f}$ Respir Dis 1986;69:142-5.

29 Stanford JL. Koch's phenomenon: can it be corrected? Tubercle 1991;72:241-9.

30 Nye PM, Stanford JL, Rook GAW, Lawton P, MacGregor M, Reily C, et al. Suppressor determinants of mycobacteria and their potential relevance to leprosy. Lepr Rev 1986;57:147-57.

31 Stanford JL, Paul RC. A preliminary report of some studies of environmental mycobacteria from Uganda. Ann Soc Belg Med Trop 1975;55:57-68.

32 Stanford JL, Paul RC, Penketh A, Thurlow S, Carswell JW, Barker DJP, et al. A preliminary study of the effect of contact with mycobacteria on the pattern of sensitivity to a range of new tuberculins amongst Ugandan adults. F Hyg 1976;76:205-14.

33 Brown JAK, Stone MM, Sutherland I. BCG vaccination of children against leprosy in Uganda. BMf 1966;1:7-14.

34 Stanford JL, Rook GAW, Samuel NM, Modlener F, Khamenei AA Nemati T, et al. Preliminary studies in search of correlates of protective immunity carried out on some Iranian leprosy patients and their families. immunity carried out on some

35 Stanford JL, Grange JM. New concepts for the control of tuberculosis in the 21 st century. $\mathcal{F} R$ Coll Phys Lond 1993;27:218-23.

36 Rook GAW, Onyebujoh P, Wilkins E, Ho Minh Ly, Al-Attiyah R, Bahr $\mathrm{GM}$, et al. A longitudinal study of agalactosyl IgG in tuberculosis patients receiving chemotherapy, with and without immunotherapy. Immunology 1994;81:149-54.

37 Khoo SH, Wilkins EGL, Fraser I, Hamour AA, Stanford JL. Lack of Tcell recognition of common mycobacterial antigens in HIV-infected individuals despite high CD4 counts. Abstract Book. International AIDS Conference, Berlin. 1993. PO-A24-0551.

38 Ingledew N, Keni M, Stanford JL, Bottasso OA. Skin test responses to new tuberculins in persons with serologic evidence of Trypanosoma cruzi tuberculins in persons with serologic evidence of Trypanosoma cruzi
infection. Lack of response to common mycobacterial antigens. Medicina infection. Lack of

39 Young DB, Garbe T. Heat shock proteins and antigens of Mycobacterium tuberculosis. Infect Immunol 1991;59:3086-93.

40 Rook GAW, Onyebujoh P, Stanford JL. Th1 $\rightarrow$ Th2 switch and loss of CD4 cells in chronic infections; an immunoendocrinological hypothesis not exclusive HIV. Immunol Today 1993;14:568-9.

41 Ramu G, Prema GD, Balakrishnan S, Shankar Narayan NP, Stanford JL A preliminary report on the immunotherapy of psoriasis. Indian Med Gaz 1990;124:381-2.

42 Stanford JL, Onyebujoh PC, Rook GAW, Grange JM, Pozniak A. Old plague, new plague and a treatment for both. AIDS 1993;7:1275-7. 